International Journal of Social Science And Human Research

ISSN(print): 2644-0679, ISSN(online): 2644-0695

Volume 04 Issue 06 June 2021

DOI: 10.47191/ijsshr/v4-i6-01, Impact factor-5.586

Page No : 1225- 1233

\title{
Estimation of Iranian Natural Gas Demand Function Using ARDL Estimation Method
}

\author{
Afsane Rafiee \\ Faculty of Accounting and Economics, South Tehran Unit, Islamic Azad University, Iran
}

\begin{abstract}
Based on its advantages and providing a big part of total energy in the country, natural gas lies in a prominent place among other energy sources. Making cognition and accurate identification of practical elements on the volume of periodic (short and long) demands on natural gas can help us outline suitable plans and policies related to energy. By this view, practical items on natural gas demands had been evaluated. The ARDL pattern with distributed interruptions and ECM model was employed to investigate the function of demands on natural gas during the years from 1976 to 2013 . The result proved all coefficients of variables in short and long periods. The natural gas price ratio confirms a contrary relation between natural gas demand and its price in the short term. This ratio in the long-term shows a direct connection between them. Related results to the electricity price ratio show that the electricity price variable has the most positive effect on natural gas demands.

Related results show that natural gas's long-term price and income strain are more than short-term ones. Also, results show that natural gas in short periods is a non-strained and necessary commodity. Being non-strained in the short-term results in a lack of efficiency of price policies. So, releasing the price of natural gas can prevent unnecessary consumption of this valuable fuel. Price strain of natural gas in long spans proves that natural gas is a complete strain commodity. This fact is based on why there is some replacement for natural gas, such as electricity and gasoline, for long periods. The minus behind income strain shows that natural gas in the long-term is as low stuff. Intersecting the price of electricity in short and long-term investigations is positive and shows a substitutional relation between electricity and natural gas. The negative intersecting strain of price of kerosene shows that natural gas and kerosene in both the short and long-term are complementary. Also, the gasoline price ratio confirms the complementary relationship in the short-term and substitutional relation in the long-term between natural gas and gasoline.
\end{abstract}

KEYWORDS: Natural Gas Demand, Energy, Iran, ARDL- Error Correction Model

\section{INTRODUCTION}

In today's world, it seems impossible to move towards economic development without considering energy. In developing countries, energy and its role as the main factor of production are also considered a source of national income. Therefore, the need to move towards economic growth in developing countries on the one hand and the fundamental role of energy in this way, on the other hand, shows the importance of recognizing energy demand in various economic sectors. Energy demand models are designed as analysis tools for policymakers and planners to decide on energy consumption and forecast energy consumption. Awareness of energy consumption can improve the decision-making process regarding the factors affecting energy consumption and the appropriate response to possible changes in these factors (Omer, 2008).

One of the most critical issues in the present age is energy constraint. Natural gas is one of these scarce energy sources that the need for planning and forecasting for its optimal distribution in countries is felt. Given the growing importance of energy and its direct relationship with the country's economic development, today, development and the continuation of life require energy. Therefore, the governments of the countries try to control the energy consumption in the desired way by planning as accurately as possible in the direction of energy consumption and correct guidance (Planning Commission, 2012)

One of the types of energy carriers is natural gas, a fossil and finite fuel, which has particular importance and status as a clean fuel due to its abundance and environmental considerations. Among energy carriers, natural gas has a unique position in terms of reserves due to its excellent success in Iran, and day by day in the energy consumption basket of Iran and the world, this energy carrier finds a better position and position. And the demand for this energy carrier, both in Iran and in the world, is increasing day by day (Jaccard, 2006).

Natural gas is recognized as one of the primary and essential sources of energy globally. According to the International Energy Agency reports, it is expected that due to the large volume of reserves, the lifespan of this God-given source will be around 120 years. Also continue (International Energy Agency, 2011). However, according to a 2011 report by the International Energy Agency, 


\section{Estimation of Iranian Natural Gas Demand Function Using ARDL Estimation Method}

on the one hand, world reserves are being allocated to meet the demand of developing countries. On the other hand, gas reserves are declining in some areas. These issues have led to threats to the security of gas supply in some regions or countries of the world.

\section{PROBLEM STATEMENT}

One of the critical issues in today's world is to create a balance between the supply and demand of energy carriers. Meanwhile, natural gas as the most vital energy carrier and consumption in most economic sectors of society (Domestic, Industrial, Commercial, Transportation, Agriculture and Public) are of particular importance.

Restrictions on non-renewable energy carriers on the one hand and world population growth

(Which is closely related to natural gas consumption) on the other hand, it has made this issue more sensitive. The above case applies to developing countries, especially Iran, for the following reasons:
A. High population growth rate
B- Restriction of technical investment in production sectors
C- Transmission and distribution problems

It has a particular sensitivity. All of the above show the importance of balancing the country's supply and demand. One of the essential points for balancing is knowing the price and revenue elasticities of natural gas in the short and long term.

As a subset of the economic system, the energy sector is responsible for meeting the energy demand of other sectors. Meeting this need requires that this sector be organized in line with changes in energy demand and consumer behaviour factors. In this regard, the energy demand obtained from the analyses is mainly deviated from the actual energy demand due to the structural constraints of the model and some inappropriate assumptions that exist and can be due to several reasons. Have. According to studies, some of these reasons include misdiagnosis of the behaviour of energy consumers and suppliers, incomplete coverage of environmental and social effects, and unrealistic economic assumptions (Alterman, 2012).

Despite sanctions, high consumption, production, and delays in gas production development projects, especially the new South Pars phases, Iran's natural gas exports have had an upward trend. In 2014, Iran's natural gas exports increased by about 4.5 per cent compared to the previous year. This year, $0.93 \%$ of Iran's gas exports have been delivered to Turkey. Since the launch of the South Pars phases, the domestic consumer market will be saturated; it will be possible to export more natural gas. To this end, increasing gas exports to European countries, Iraq and the countries on the southern shores of the Persian Gulf are options that are being considered for the development of Iran's gas trade. In 2014, gas exports were 2.2 billion cubic meters more than imports, which indicates a positive balance of Iranian gas exports (Azadi et al., 2017).

Consumption of natural gas in Iran is several times higher than the average level of global gas consumption and higher than the level of consumption of the most populous countries globally, including China, India and Indonesia. Turning to these issues, it can be noted that the supply of energy to the country's domestic and commercial sectors, especially natural gas, regardless of the optimization problems or incompatibility of production with consumption, will create problems (Dong et al., 2017). For this purpose, it is necessary to carefully study the factors affecting the demand for natural gas and use them in energy and macroeconomic policies. One of these economic phenomena is the relationship between the demand for energy carriers, including natural gas, and the factors and variables that affect it. Therefore, in recent years, many studies have proposed using structural change models to investigate the nonlinear and asymmetric behaviour of energy carrier demand (Coady et al., 2019).

Iran can achieve a good position by expanding and developing its natural gas production capacities through various means such as attracting foreign investment and improving technology. Therefore, in the present study, natural gas demand factors are examined while theoretically analyzing the issue. Long-term effects are analyzed through time-series analyses using a self-explanatory dynamic model. The provider pays with Distributed Intervals (ARDL). Estimating the above model makes it possible to study the consumption situation and price of natural gas in the country and examine the long-term effects of variables affecting natural gas demand.

\section{RESEARCH HYPOTHESIS}

1- What is the relationship between natural gas consumption and per capita income?

2. What is the relationship between natural gas demand and electricity prices?

3. What is the relationship between natural gas demand and the price of petroleum products?

Hypotheses:

1- The income elasticity of natural gas demand is positive.

2- The demand for natural gas is positive about the price of electricity.

3- The elasticity of natural gas demand to the price of petroleum products is positive.

\section{RESEARCH PURPOSES}

The primary purpose of this study is to estimate the natural gas demand function based on economic variables affecting demand, such as per capita income and gas prices. In this study, alternative fuels and gas supplements have been used as variables affecting 


\section{Estimation of Iranian Natural Gas Demand Function Using ARDL Estimation Method}

natural gas demand to estimate the model. Also, this research aims to assess the price elasticity and income of natural gas and determine the most critical factors affecting the natural gas demand function.

\section{Research Variables:}

The dependent variable:

Consumption of natural gas: Natural gas is a clean fuel and has become very popular worldwide in recent decades due to the low level of environmental pollution it generates. In Iran, the central axis of development of the gas industry, especially after the revolution, is based on gas consumption to meet the country's energy needs, and this trend is still ongoing. Consumption of natural gas, especially as a substitute for gas instead of petroleum products, can lead to economic security. Because with the replacement of gas, the intensity of consumption of petroleum products is reduced, and the ground for increasing the export potential of crude oil is provided. Gas in the Iranian economy has always been considered a production factor along with manpower and capital. In addition to increasing the amount of natural gas consumption in the country, the study of natural gas consumption trends in recent years indicates an imbalance between consumption options and gas allocation citizenship from random variables such as weather conditions and political issues. It is security. Injecting gas into oil reservoirs increases the recovery rate of crude oil on the one hand. It preserves the income rights of the next generation due to storing the gas injected in underground reservoirs for future harvesting on the other hand (Sehatpour et al., 2017).

Independent variables include:

- Natural gas prices: Natural gas prices are an essential and effective variable on natural gas demand. The nature of the natural gas industry in Iran is monopolistic, and the energy-intensive nature of the energy sector means that this sector requires a lot of investment. Since more equipment provides economic savings, a limited number of Large suppliers will control the market. The maximum profit-optimizing price for a sole proprietor is the price at which the final cost equals the last revenue. But since the monopolist is facing a downward demand curve, the absolute income will be lower than the price (Goncharuk, 2013).

- Electricity prices: Electricity as a source of energy required by various economic sectors on the one hand and as an indicator of social welfare, on the other hand, is of particular importance. In Iran, payments made by electricity subscribers are not based on the cost of electricity but on tariffs that have been influenced by several economic, social and political issues. Tariffs can be an effective tool for optimizing customers' electricity consumption, but failure to modify it in proportion to the increase in costs will lead to excessive electricity consumption (Schröder \& Kuckshinrichs, 2015).

- Prices of petroleum products: A study of the historical trends in oil and natural gas prices shows that the oil and natural gas markets are closely related. Natural gas is the closest substitute for oil. There is a long-term relationship between oil, crude, and natural gas prices, while there is no immediate alternative in the short term. The oil market is international, while the gas market is regional and small. Its price is determined by agreements between the parties (gas suppliers and demanders), determining oil price. Play a key role in determining gas prices (Aloui et al., 2014).

- Per capita income: Per capita income is one of the most important criteria used to assess economic well-being. On the other hand, this variable shows the share of each member of society in the country's GDP. It indicates the ability to produce value-added by the population of countries. On the other hand, many reputable international organizations use countries' per capita incomes to assess the well-being of households and the quality of living standards in different countries. Despite efforts to provide appropriate benchmarks or criteria for accurately evaluating the welfare of individuals in a country, no alternative to national per capita income / GDP has been provided so far. Given the importance of this variable, the Organization for Economic Co-operation and Development (OECD) uses the per capita GDP of countries to calculate a better life index and ranks its member countries. The World Bank also announces the per capita GDP of different world countries every year (Bérenger \& Verdier-Chouchane, 2007).

\section{DATA COLLECTION METHOD}

The data used in the present study are to estimate the natural gas demand function as an annual time series that covers 1976 t0 2013. The method of data collection is in the form of libraries and the use of reputable sites. Data related to the price of energy carriers (electricity, gasoline, kerosene) and the amount of natural gas consumption from the energy balance sheet of the Ministry of Energy and natural gas price data from the gas supply company and per capita income are extracted and collected from the Central Bank website. Eviews 9 software has been used to estimate the model.

\section{Estimation of Model Parameters}

After describing the variables used in the model, we describe the results obtained. Table 1 presents descriptive statistics related to the variables used in the present study. As can be seen, there is not much difference between the minimum and maximum values, but all variables have an upward trend in the study period. 


\section{Estimation of Iranian Natural Gas Demand Function Using ARDL Estimation Method}

Table 1: Descriptive statistics of variables during the period 1976 to 2013

\begin{tabular}{|c|c|c|c|c|c|}
\hline $\begin{array}{c}\text { Standard } \\
\text { deviation }\end{array}$ & Minimum & Maximum & Middle & Average & Variable \\
\hline $1 / 224739$ & $7 / 658228$ & $11 / 56297$ & $10 / 24392$ & $9 / 918935$ & LGN \\
\hline $1 / 765075$ & $0 / 993252$ & $6 / 618739$ & $2 / 890372$ & $3 / 038660$ & LPN \\
\hline $0 / 302925$ & $2 / 107844$ & $3 / 276539$ & $2 / 735245$ & $2 / 797705$ & LYN \\
\hline $1 / 746090$ & $0 / 875469$ & $6 / 036677$ & $3 / 841601$ & $3 / 423955$ & LPE \\
\hline $1 / 721369$ & $2 / 302585$ & $8 / 294050$ & $4 / 867534$ & $5 / 111425$ & LPG \\
\hline $1 / 882790$ & $0 / 916291$ & $6 / 907755$ & $3 / 401197$ & $3 / 476532$ & LPO \\
\hline
\end{tabular}

To estimate the model by the ARDL method, first, the variables should be examined in terms of reliability and the existence of a cumulative relationship between independent and dependent variables. For this purpose, econometric methods, especially the least-squares method, the conventional way and the ARDL aggregate method, estimate the parameters. The unit root method and the generalized Dickey-Fuller test are used to study the static variables.

\section{Unit Root Test Results}

To avoid false regressions, the stativity of each of the research variables has been investigated using the generalized Dickiofuller unit root test. The results obtained for all the studied variables are given in Tables 2 and 3.

According to Table 2, based on static tests, all variables are at a varying level. Concerning these variables, where the absolute value of the calculated statistical value is less than the critical value, due to the lack of significance at the 5\% level, the assumption of the absence of a single root can be rejected, and the instability of these variables can be judged at the level.

Table 2: Generalized Dickey-Fuller (ADF) static test of model variables at zero level

\begin{tabular}{|l|c|c|c|}
\hline Single root & Critical DF values 95\% & Computational DF values & Variable \\
\hline Unstable & $-2 / 95$ & $-1 / 31$ & LGN \\
\hline Unstable & $-2 / 19$ & $5 / 36$ & LPN \\
\hline Unstable & $-2 / 98$ & $-1 / 48$ & LPE \\
\hline Unstable & $-2 / 95$ & $-0 / 17$ & LPG \\
\hline Unstable & $-2 / 95$ & $-0 / 18$ & LPO \\
\hline Unstable & $-2 / 95$ & $0 / 04$ & \\
\hline
\end{tabular}

Differentiation was performed to determine the static degree, the results of which can be seen in Table 2. According to this table, all variables are static in the first-order difference state and have a static degree (1). As shown in the table, the value of the test statistic for the natural gas consumption logarithm variable is -5.14 , the absolute value of which is greater than the critical value (-2.95). It is significant at the $5 \%$ level. The logarithm variables of natural gas price, per capita income logarithm, electricity price logarithm, gasoline price logarithm and white oil price logarithm have the values of test statistics of $-4.38,-7.17,-4.00,-7.02$, and 6.02 , respectively, are that the absolute value of all of them is greater than the critical values of -2.95 , so the hypothesis of the absence of a single root is not rejected. The mentioned variables are statically differentiated once.

Table 3: Generalized Dickey-Fuller (ADF) static test of model variables at level 1

\begin{tabular}{|l|c|c|l|}
\hline Single root & Critical DF values 95\% & Computational DF values & Variable \\
\hline -static I(1) & $-2 / 95$ & $-5 / 14^{* *}$ & LGN \\
\hline -static I(1) & $-2 / 95$ & $-4 / 38^{* *}$ & LPN \\
\hline -static I(1) & $-2 / 95$ & $-7 / 17^{* *}$ & LYN \\
\hline -static I(1) & $-2 / 95$ & $-4 / 00^{* *}$ & LPE \\
\hline -static I(1) & $-2 / 95$ & $-7 / 02^{* *}$ & LPG \\
\hline -static I(1) & $-2 / 95$ & $-6 / 02^{* *}$ & LPO \\
\hline
\end{tabular}




\section{Estimation of Iranian Natural Gas Demand Function Using ARDL Estimation Method}

\section{Collective Test}

Before estimating long-term coefficients by the ARDL method, it is necessary to perform a cumulative test to ensure a longterm relationship between explanatory and dependent variables.

In this section, the aggregate test is performed using the Johansson-Josilius method to find long-run equilibrium relationships between variables. In this method, first, two trials of maximum eigenvalue and effect test determine the number of aggregate vectors. Johansson-Josilius state that in the event of a discrepancy between the results of these two tests in determining the number of congruent vectors, since the maximum eigenvalue has a more definite opposite assumption, this test is preferable to the effect test. Then, suppose the existence of an integral relation is proved based on one of the desired variables. In that case, the normalization operation is performed on the mentioned vectors and based on the economic theory, the integrative vectors that have an economic interpretation are selected.

The results of the Johansson-Josilius test are given in Tables 4 and 5. As can be seen in the above tables, the effect test confirms three long-run equilibrium relationships. The maximum eigenvalue test confirms the existence of a long-term equilibrium relationship between the variables. Since there is a discrepancy between the results and the results of the maximum eigenvalue test have a more definite opposite assumption, the existence of a long-run equilibrium relationship between the variables is confirmed.

Table 3: Johansson-Josilius aggregate test results (effect matrix)

\begin{tabular}{|c|c|c|c|}
\hline 95\% probability value & $\begin{array}{l}\text { Critical importance at } \\
\text { 95\% level }\end{array}$ & Value of test statistics & Hypothesis zero \\
\hline $0 / 0000$ & $95 / 75366$ & $145 / 8354$ & $\mathrm{r}=0 *$ \\
\hline $0 / 0035$ & $69 / 81889$ & $82 / 45288$ & $\mathrm{r} \leq 1 *$ \\
\hline $0 / 0287$ & $47 / 85613$ & $50 / 46492$ & $\mathrm{r} \leq 2 *$ \\
\hline $0 / 1124$ & $29 / 79707$ & $26 / 57704$ & $\mathrm{r} \leq 3$ \\
\hline $0 / 1780$ & $15 / 49471$ & $11 / 58469$ & $\mathrm{r} \leq 4$ \\
\hline $0 / 7865$ & $3 / 841466$ & $0 / 073387$ & $\mathrm{r} \leq 5$ \\
\hline
\end{tabular}

Table 4: Johansson-Josilius aggregate test results (maximum eigenvalues)

\begin{tabular}{|c|c|c|c|}
\hline 95\% probability value & $\begin{array}{l}\text { Critical importance at } \\
\text { 95\% level }\end{array}$ & Value of test statistics & Hypothesis zero \\
\hline $0 / 000$ & $40 / 07757$ & $63 / 38351$ & $\mathrm{r}=0 *$ \\
\hline $0 / 0826$ & $33 / 87687$ & $31 / 98796$ & $\mathrm{r} \leq 1$ \\
\hline $0 / 1387$ & $27 / 58434$ & $23 / 88788$ & $\mathrm{r} \leq 2$ \\
\hline $0 / 2894$ & $21 / 13162$ & $14 / 99235$ & $\mathrm{r} \leq 3$ \\
\hline $0 / 1304$ & $14 / 26460$ & $11 / 51131$ & $\mathrm{r} \leq 4$ \\
\hline $0 / 7865$ & $3 / 841466$ & $0 / 073387$ & $\mathrm{r} \leq 5$ \\
\hline
\end{tabular}

We can also use the method of calculating the t-statistic and the critical quantity presented by Banerji, Dolado to determine the cohesive relationship. The requirement to adjust the estimated dynamic pattern toward the long-run equilibrium is that the sum of the coefficients for the interval-dependent variable is less than one. The quantity of t-statistic required to perform the above test is calculated as follows:

$$
\begin{aligned}
& \mathrm{t}=\frac{\sum_{i=1}^{p} \widehat{\alpha l}-1}{\sum_{i=1}^{p} \delta \widehat{\alpha \mathrm{l}}} \\
& \mathrm{t}=\frac{0 / 718-1}{0 / 046}=-6 / 13
\end{aligned}
$$

The absolute value of the calculated t-statistic is higher than the absolute value of the Dolado and Master statistic at the 5\% significance level, which is -4.43 , so the null hypothesis that there is no long-run equilibrium relationship between natural gas consumption can be and reject explanatory variables and confirm the existence of a long-run equilibrium relationship between the model variables. Considering the confirmation of a long-run equilibrium relationship at the $95 \%$ confidence level between the model variables, the results can be analyzed by ensuring the absence of false regression between the model variables.

\section{Short-term Estimate}

The models explain the optimal intervals for the natural gas demand pattern. Based on this criterion, for the explanatory variables of natural gas price and per capita income and the dependent variable, the optimal interval three was selected. 4 optimal 


\section{Estimation of Iranian Natural Gas Demand Function Using ARDL Estimation Method}

interruptions were determined for the variables of electricity price, gasoline price and kerosene price. Thus, the self-explanatory model with extended intervals was considered as [ARDL $(3,3,3,4,4,4)]$. According to the results, it is clear that the optimal number of interruptions for natural gas demand has been determined. This means that the change in demand for natural gas in the last three periods affects the demand for natural gas in the current period. Also, the difference in natural gas prices and per capita income in the previous three periods and the change in electricity prices, gasoline prices and kerosene prices in the last four periods affect the demand for natural gas in the current period.

Table 5: Results of estimating the natural gas demand model error correction model

\begin{tabular}{|l|c|c|c|c|}
\hline Possibility & Statistic t & Standard deviation & Coefficients & Variable \\
\hline $0 / 0005$ & $-10 / 419$ & $0 / 038$ & $*_{-}-0 / 401$ & D(LPN) \\
\hline $0 / 0002$ & $13 / 686$ & $0 / 037$ & $*_{*} 0 / 515$ & D(LYN) \\
\hline $0 / 0080$ & $4 / 900$ & $0 / 102$ & $*_{*} 0 / 503$ & D(LPE) \\
\hline $0 / 0111$ & $-4 / 466$ & $0 / 034$ & $*_{-} 0 / 153$ & D(LPG) \\
\hline $0 / 0029$ & $-6 / 489$ & $0 / 030$ & $*_{-0}-0 / 197$ & D(LPO) \\
\hline $0 / 0000$ & $-20 / 909$ & $0 / 031$ & & Ecm(-1) \\
\hline & $\begin{array}{c}\text { F- } \\
\mathrm{R}^{2}=0 / 999\end{array}$ & $\begin{array}{l}\text { Prob(F-statistics })= \\
0 / 000001\end{array}$ & & \\
\hline
\end{tabular}

To investigate the short-term relationships between natural gas demand and other explanatory variables, the error correction model is used, the results of which are shown in Table 5.

As shown in Table 5, the negative coefficient of natural gas price (-0.4) indicates that natural gas consumption in the short run is inversely related to its price, so The law of demand is established. In other words, with a $1 \%$ increase in the price of natural gas, the consumption of natural gas decreases by $0.4 \%$. There is an inverse and correct relationship between gas prices and natural gas consumption in the short-run model, which has a reasonable degree of significance. The above coefficient shows that the demand for natural gas is inflexible relative to its price in the short run.

The per capita income coefficient is significant and positive and indicates that with a $1 \%$ increase in revenue, we will have a $0.52 \%$ increase in natural gas consumption. On the other hand, this coefficient's value indicates that commodity natural gas is essential in the short run.

The electricity price coefficient is 0.503 , which is significant and positive and indicates that if other coefficients are constant, with a $1 \%$ increase in electricity prices, natural gas consumption will increase by $0.5 \%$. This coefficient shows the positive relationship between natural gas demand and electricity prices and indicates the substitution relationship between electricity and natural gas.

The coefficients of petroleum products, including gasoline and kerosene, have been -0.153 and -0.197 , respectively, which are significant and indicate that if the other coefficients are constant in the short run, there is a negative relationship between natural gas demand and the price of petroleum products. In other words, a 1 per cent increase in the price of gasoline and kerosene reduces natural gas consumption by 0.15 per cent and approximately 0.2 per cent, respectively, and a negative sign indicates that oil and natural gas products are complementary.

The error correction pattern relates short-term fluctuations of variables to their long-term values. The results obtained from the short-term error correction model, which represents the adjustment speed, are significant, and the expression ECM (-1) in this model has a positive sign of expectation. Therefore, it can be said that the long-run equilibrium can be accessible. Based on this table, the coefficient of the error correction variable is -0.6 . It shows that $60 \%$ of the imbalance of the dependent variable is adjusted towards the long-run relationship in each period. In general, the presented model results indicate that the move towards equilibrium takes place over six years.

Table 6: Bruce Pagan Godfrey Autocorrelation Test

Heteroskedasticity Test: Breusch-Pagan-Godfrey

\begin{tabular}{llll}
\hline \hline & & & \\
F-statistic & 0.498797 & Prob. F(26,4) & 0.8766 \\
Obs*R-squared & 23.69244 & Prob. Chi-Square(26) & 0.5935 \\
Scaled explained SS & 0.353310 & Prob. Chi-Square(26) & 1.0000 \\
\hline \hline
\end{tabular}




\section{Estimation of Iranian Natural Gas Demand Function Using ARDL Estimation Method}

The value of the coefficient of determination of this model also indicates that the explanatory variables in the model explain 99\% of the changes in natural gas demand. The Brugan Pagan Godfrey test measured the autocorrelation of the model, and the obtained results confirmed the lack of autocorrelation between the coefficients.

\section{Long-term estimates}

The results for estimating the long-run relationship between natural gas demand are shown in Table 6. According to the logarithmic form of the variables, the coefficients represent the elasticity.

Table 6: Results of estimating long-term coefficients of natural gas demand function

\begin{tabular}{|l|l|c|l|l|}
\hline Possibility & Statistic t & Standard deviation & Coefficients & Variable \\
\hline $0 / 0005$ & $10 / 542$ & $0 / 126$ & $1 / 334 * *$ & LPN \\
\hline $0 / 0003$ & $-11 / 911$ & $0 / 106$ & $-1 / 272 * *$ & LYN \\
\hline $0 / 0000$ & $25 / 372$ & $0 / 064$ & $1 / 632 * *$ & LPE \\
\hline $0 / 0003$ & $11 / 720$ & $0 / 105$ & $1 / 236 * *$ & LPG \\
\hline $0 / 0001$ & $-14 / 618$ & $0 / 200$ & $-2 / 934 * *$ & LPO \\
\hline $0 / 0000$ & $28 / 933$ & $0 / 268$ & $7 / 764 * *$ & Width of origin \\
\hline
\end{tabular}

According to the results, the natural gas price coefficient, in the long run, is 1.33 and positive and significant and shows that there is a direct relationship between the price of natural gas and its demand in the long run. The figure also shows that a 1 per cent increase in natural gas prices will increase natural gas demand by 1.3 per cent in the long run. The above coefficient indicates the elasticity of natural gas in the long run.

In the long run, the per capita income coefficient is statistically significant and equal to -1.27 , which indicates that a one per cent increase in per capita income, assuming other factors are constant, causes a decrease of approximately 1.3 per cent. Will be in demand for natural gas. The coefficient obtained means that natural gas is a low commodity in the long run.

The results also show that the electricity price logarithm has the most positive effect on natural gas demand and is signific ant at the $95 \%$ confidence level. Therefore, the elasticity of cross-demand of natural gas and electricity prices, in the long run, is positive and greater than one with an exact value of 1.63, which indicates the high sensitivity of natural gas demand to changes in electricity prices as a substitute commodity. By constantly considering other variables, a one per cent increase in electricity prices will result in a 1.63 per cent increase in natural gas demand. In the long run, if the price of electricity rises, we can move towards more natural gas consumption, so the demand for natural gas will increase.

According to the results of Table 6, the logarithm of gasoline price, which is statistically significant at a 95\% confidence level, also has a positive effect on natural gas demand. The value of this coefficient is 1.23 , which indicates the sensitivity of natural gas demand to changes in gasoline prices. The positive coefficient of gasoline price means a substitution relationship between gasoline and natural gas in the long run. The value of the obtained kerosene coefficient is -2.934 , which is significant and indicates that a $1 \%$ increase in the price of kerosene will cause a $2.9 \%$ decrease in natural gas demand in the long run. The sign of this coefficient also indicates that kerosene and natural gas are complementary in the long run.

Comparing short-term and long-term coefficients of natural gas prices shows an inverse relationship between natural gas demand and its price in the short run. With increasing natural gas prices, its demand decreases. Still, this relationship in the long run Is. Per capita income coefficients indicate that natural gas is an essential commodity in the short run and a low item in the long run. As demand increases, the demand for natural gas decreases. The elasticity of electricity prices to natural gas is positive in the short and long term and indicates a substitution relationship between the two commodities. The negative coefficient of kerosene price in the short and long time indicates that these two products are complementary. The negative coefficient of gasoline price in the short term has a complementary relationship, and its positive coefficient has a substitution relationship for a long time. Refers to gasoline and natural gas. Also, the comparison of long-term and short-term coefficients shows that long-term elasticities are more than short-term elasticities, which has an economic logic in the demand function.

The effect of changes in natural gas prices and per capita income on natural gas demand can be measured using price and revenue elasticity. Price elasticity of demand is a measure by which natural gas demand changes to changes in its price can be studied. According to the estimated coefficients, the price and revenue elasticity of demand for natural gas in the short, long and long term in the period under discussion will be as follows: 


\section{Estimation of Iranian Natural Gas Demand Function Using ARDL Estimation Method}

Table 7: Price and revenue elasticity of natural gas demand

\begin{tabular}{|l|l|}
\hline Natural gas input & Description \\
\hline$-0 / 40$ & Short-term price pull \\
\hline $1 / 33$ & Long-term price pull \\
\hline $0 / 51$ & Short-term income elasticity \\
\hline$-1 / 27$ & Long-term income elasticity \\
\hline
\end{tabular}

According to the figures in Table 7, it can be seen that the absolute value of the long-term elasticity of the natural gas price is more significant than its absolute value in the short run. This indicates that the response to the relative changes in the price of this input over time is not the same.

In the logarithmic model, the price coefficient indicates the elasticity of the commodity. This coefficient shows what effect the increase in the price of goods has on the consumption of goods. If the absolute value of this coefficient is between zero and one, the commodity will pull, and if this coefficient is more significant than one, the item will pull. According to the figures shown in Table 7, the short-term price elasticity of natural gas is low and shows that natural gas is an inelastic commodity in the short run. Since this coefficient in the estimated equation is close to zero, it shows that in the short run, in the face of rising natural gas prices, consumption does not decrease much, and this means low efficiency of price policy in the short run. In a way, it can be said that changes in demand in the years under review have not been sensitive to changes in natural gas prices. The inelasticity of natural gas demand is because the substitute for this energy carrier is meager in the short term.

The price elasticity of natural gas demand, according to Table 7, is 1.33 in the long run, which can be said that in the long run, natural gas demand is elastic to its price changes, and the demand for natural gas is sensitive to price changes. With rising prices for natural gas, demand for it increases due to substituting goods such as electricity and gasoline for natural gas in the long run.

We now examine the revenue elasticity of natural gas demand. According to theories of microeconomics, a coefficient more significant than one indicates the luxury of the commodity, and a coefficient smaller than zero indicates the inferiority of the item, and a coefficient between zero and one indicates the necessity (ordinary) of the commodity.

Revenue elasticity for natural gas in the short term is 0.515 . The coefficient obtained means that, firstly, natural gas is a necessary commodity in the short run. Secondly, a $1 \%$ increase in revenue in the short run increases natural gas consumption by $0.52 \%$. This coefficient is -1.227 in the long run. Its negative sign indicates that natural gas is a low commodity in the long run. With increasing income, the demand for this commodity decreases by 1.27 per cent.

\section{CONCLUSION}

The present study results indicate that all coefficients are significant in the short and long term at the 95\% confidence level. The results show an inverse relationship between the price of natural gas and its demand in the short run, which is by the law of demand. Changes in natural gas demand relative to its price are inelastic. The inelasticity of natural gas in the short run will make the price policy inefficient, so liberalizing the price of natural gas can prevent the excessive consumption of this critical fuel in the country. But this relationship is direct in the long run. With the increase in natural gas prices, the demand for this commodity increases, and changes in the demand for natural gas relative to its price are attractive. Revenue elasticity also showed that natural gas is an essential commodity in the short run and a common thing in the long run. The results also showed that the price and revenue elasticity of natural gas, in the long run, was higher than in the short run, which is consistent with the results of other domestic and foreign studies. The crossover elasticity of electricity prices to natural gas demand indicates a substitution relationship between the two commodities in the short and long term. The crossover elasticity of petroleum products prices to natural gas demand in the short run indicates that natural gas and petroleum products (gasoline and kerosene) are complementary. In the long run, there is a perfect relationship between kerosene and natural gas. Still, the favourable elasticity of gasoline prices and natural gas demand indicates a substitution relationship between the two goods. Now examine the research hypotheses:

According to the first hypothesis, the revenue elasticity of natural gas demand is positive. According to the results obtained in the short run, the demand for natural gas has a positive sign for changes in income, and natural gas is a necessary commodity, so the above hypothesis is confirmed in the short run. Still, it has a negative sign in the long run compared to revenue changes, and natural gas is a low commodity in the long run. Therefore, the first hypothesis is rejected in the long run and confirmed in the short run.

According to the second hypothesis, the elasticity of natural gas demand to electricity prices is positive. The study of the intersection of natural gas demand concerning electricity prices and the effect of electricity prices as a substitute commodity for natural gas shows a positive relationship between natural gas consumption and electricity prices in the long run and short term. Therefore, according to the hypotheses presented in this study, the second hypothesis is accepted, and the positive correlation between natural gas demand and electricity prices is confirmed. 


\section{Estimation of Iranian Natural Gas Demand Function Using ARDL Estimation Method}

According to the third hypothesis, the elasticity of natural gas demand relative to the price of petroleum products is positive. Given the effectiveness of petroleum products on the consumption of natural gas, it can be said that the price of petroleum products can be used as a tool to control and guide the consumption of natural gas. The significance of the estimated coefficient of the price of petroleum products about gas consumption and its sign indicates a complementary relationship between natural gas and petroleum products. According to the results obtained in the short term, the elasticity of natural gas demand to the price of petroleum products has a negative sign, thus rejecting the hypothesis. In the long run, the above crossover tension is negative for kerosene and kerosene, and natural gas is complementary. Still, for gasoline, this tension is positive, and gasoline and natural gas are substitutes. Therefore, by comparing the short-term and long-term results, the third hypothesis is rejected.

\section{SUGGESTIONS}

- Considering the number of gas reserves in the country and the positive effects on the environment, and the ability to replace natural gas instead of valuable oil products, replacing natural gas with other energy carriers is a commitment. According to model estimation results in the long and short term and the effectiveness of natural gas and electricity prices to control natural gas consumption, natural gas and electricity prices can be considered an effective tool. On the other hand, the price of petroleum products as a tool affecting the demand for natural gas is effective.

- The inelasticity of natural gas in the short run will make the pricing policy inefficient. Thus, the liberalization of natural gas prices can increase the efficiency of price policy. At the same time, liberalizing the price of natural gas can prevent the excessive and high consumption of this critical fuel in the country. In parallel with the price liberalization process to reduce natural gas consumption, fuel consumption should be replaced with other fuels such as electricity.

- Considering that in this research, using demand-side ARDL model and considering supply-side constraints, demand elasticities have been investigated, so it is suggested that in future studies, gas supply and demand Natural should be examined simultaneously to calculate better interpret the above effects.

\section{REFERENCE}

1) Omer, A. M. (2008). Energy, environment and sustainable development. Renewable and sustainable energy reviews, 12(9), 2265-2300.

2) Planning Commission. (2012). Twelfth Five Year Plan (2012-2017). Faster, More Inclusive and Sustainable Growth. Vol. I.

3) Prices, I. E. (2011). International Energy Agency. Energy Prices and Taxes, 2011(1).

4) Jaccard, M. (2006). Sustainable fossil fuels: the unusual suspect in the quest for clean and enduring energy. Cambridge University Press.

5) Alterman, S. (2012). Natural gas price volatility in the UK and North America. Oxford Institute for Energy Studies.

6) Azadi, P., Sarmadi, A. N., Mahmoudzadeh, A., \& Shirvani, T. (2017). The Outlook for natural gas, electricity, and renewable energy in Iran. Stanford Iran, 2040, 1-27.

7) Dong, K., Sun, R., \& Hochman, G. (2017). Do natural gas and renewable energy consumption lead to less CO2 emission? Empirical evidence from a panel of BRICS countries. Energy, 141, 1466-1478.

8) Coady, M. D., Parry, I., Le, N. P., \& Shang, B. (2019). Global fossil fuel subsidies remain large: an update based on country-level estimates. International Monetary Fund.

9) Sehatpour, M. H., Kazemi, A., \& Sehatpour, H. E. (2017). Evaluation of alternative fuels for light-duty vehicles in Iran using a multi-criteria approach. Renewable and Sustainable Energy Reviews, 72, 295-310.

10) Goncharuk, A. G. (2013). What causes an increase in gas prices: the case of Ukraine. International Journal of Energy Sector Management.

11) Schröder, T., \& Kuckshinrichs, W. (2015). Value of lost load: An efficient economic indicator for power supply security? A literature review. Frontiers in energy research, 3, 55.

12) Aloui, R., Aïssa, M. S. B., Hammoudeh, S., \& Nguyen, D. K. (2014). Dependence and extreme dependence of crude oil and natural gas prices with applications to risk management. Energy Economics, 42, 332-342.

13) Bérenger, V., \& Verdier-Chouchane, A. (2007). Multidimensional measures of well-being: Standard of living and quality of life across countries. World Development, 35(7), 1259-1276. 